\title{
Problems in packaging and delivery combined with countermeasures in design education
}

\author{
Li Ya \\ Shanghai University of Engineering Science \\ Room 409, Art Building, 333 Longteng Road \\ Shanghai, China \\ 13601822312,739588595@qq.com
}

\begin{abstract}
According to the delivery behavior of express parcels in a residential area in Shanghai, observe the behavior patterns of couriers and people in the process of delivery, so as to explore the problems of packaging in express delivery, and propose improved suggestions and measures for express packaging. The above situation proposes countermeasures for the education of packaging design in undergraduate education. Research methods: through observation, data statistics and analysis. As a result, it was found out from the observations that: 1 . Due to the concentrated concentration and large quantity of courier packaging in the residential area, the general courier service was not delivered to the door. 2 . The loss of the parcel was caused by the limitation of the delivery site. 3 . The part of the package was made public. Storage is easy to cause leakage of personal information. 4, the current environmental problems caused by express packaging. It is recommended to increase the research on information processing, logistics data and environmentally friendly packaging materials in undergraduate education in packaging design.
\end{abstract}

Key words: express delivery, behavioral observation, and packaging design professional education

\section{Introduction}

According to the 2016 postal industry development statistics bulletin data, in 2016 the annual courier service business volume completed 31 billion 280 million, an increase of $51.4 \%{ }^{[1]}$. In this study, the parcel delivery of a large residential area in Shanghai was taken as the object of study. The quantity of express delivery and the storage of Express items were investigated. Inductively observe the results of the analysis and make recommendations in undergraduate packaging design education.

\section{1, The status of e-commerce in China}

China's current e-commerce is a stable period of development, in 2015 China's online shopping market transactions amounted to 3 trillion and 800 billion yuan, an increase of $36.2 \%$. Online shopping accounted for $12.6 \%$ of total retail sales of consumer goods, an increase of $2 \%$. ${ }^{[2]}$ Compared to 2014. According to the 2016 postal industry development statistics bulletin data show that: in 2017 the rapid growth of the National Express service. Full year courier service business volume completed 31 billion 280 million, an increase of $51.4 \%$, express service revenue was 397 billion 440 million yuan, an increase of $43.5 \%{ }^{[3]}$.

\subsection{Express packaging industry problems}

Ruan Ping (2017) in the Green Express package proposed a power driven study, consumers demolished parcels will directly throw express package accounted for $74.55 \%$, accounting for $9.09 \%$ of all sell scrap and other purposes, and for saving consumers receive less, accounted for only $7.27 \%$. In 2015 , China's express industry used a total of about 3000000000 woven bags, the number of packaging boxes for 9 billion 922 million, the tape reached 16 billion 985 million meters ${ }^{[4]}$. The data show that the number of express packaging materials used in our country is large, and the recycling rate is low.

\section{Research methods}

In this study, non participant observation (Non-participant, observation) was used to observe the delivery of a large residential area in Shanghai. Observations were made at work day times and divided into six observations. They are 9:00-11:00 in the morning (120 minutes), and 14:00-16:00 (120 minutes) in the afternoon. Detailed records of the delivery of each courier, including the number of delivery, the attitude of the move, the location of the courier, and other information. Located in the corner of the first floor lobby of No. 7-8 residential building, it does not affect the residents and express delivery. The actual field of view can clearly observe what is happening in the hall. Before the observation, the phenomenon that you want to observe is as follows: (1) the delivery situation of the courier including delivery time, parcel number, parcel packing and package placement, etc. (2) package storage and collection.

\section{Observations}

The results are recorded in Table 1 to table 2 respectively. The number of express parcel delivery and the number of couriers in two different time periods are as follows:

Table 1 express parcel delivery

Observation target: delivery parcel number and delivery location Observation period: 9:00-11:00

\begin{tabular}{llll}
\hline $\begin{array}{l}\text { date of par } \\
\text { inspection }\end{array}$ & $\begin{array}{l}\text { delivery } \\
\text { cel } \\
\text { nu } \\
\mathrm{mb} \\
\mathrm{er}\end{array}$ & $\begin{array}{l}\text { number } \\
\text { of } \\
\text { couriers }\end{array}$ \\
\hline 2017.8 .3 & 93 & $\begin{array}{l}\text { Fengchao, } \\
\text { lobby } \\
\text { Fengchao, } \\
\text { lobby }\end{array}$ & 6 \\
\hline
\end{tabular}




\begin{tabular}{|c|c|c|c|}
\hline 2017.8 .7 & $\begin{array}{l}10 \\
4\end{array}$ & \multicolumn{2}{|c|}{7} \\
\hline \multicolumn{4}{|c|}{$\begin{array}{c}\text { Table } 2 \text { express parcel delivery } \\
\text { Table } 2 \text { observation target: delivery parcel numbe } \\
\text { position } \\
\text { Observation period: } 14: 00-16: 00 \\
\text { Number, date of inspection, parcel number, deli } \\
\text { number of couriers }\end{array}$} \\
\hline $\begin{array}{l}\text { date of } \\
\text { inspection }\end{array}$ & $\begin{array}{l}\text { parcel } \\
\text { numb } \\
\text { er }\end{array}$ & $\begin{array}{l}\text { delivery } \\
\text { position }\end{array}$ & $\begin{array}{l}\text { number } \\
\text { of } \\
\text { couriers }\end{array}$ \\
\hline 2017.8 .3 & 32 & $\begin{array}{l}\text { Fengchao, } \\
\text { lobby }\end{array}$ & 3 \\
\hline 2017.8 .4 & 27 & $\begin{array}{l}\text { Fengchao, } \\
\text { lobby }\end{array}$ & 2 \\
\hline 2017.8 .7 & 48 & $\begin{array}{l}\text { Fengchao, } \\
\text { lobby }\end{array}$ & 4 \\
\hline
\end{tabular}

\subsection{Delivery of express delivery}

Daily delivery time ranges from 8:00 to 22:00, and delivery in the morning is more concentrated than in the afternoon and evening. The placement of the express parcel is the newly-installed Fengchao intelligent express cabinet outside the residential building and the ground floor of the first floor. The placement time of the express cabinet is June 2017. The express cabinet has a total of 110 storage tanks, which can be stored and extracted for recycling. Observed that the courier used the storage cabinet is more skilled, and is the first choice as a delivery package. Most couriers will first select the Fengchao Smart Express Cabinet outside the residential building, as shown in Figure 1. If the courier is full, or the size of the parcel is too large to be placed in the courier, it can only be stacked on the lobby floor. Some cautious couriers will also leave the extra express package in the corner of the lobby. Check back later to see if there is an empty box to deposit more courier packages to prevent the parcel from being lost in the lobby. Of course, there are also couriers who are not willing to deposit the courier package in the Fengchao Express Cabinet, because each package will charge a storage fee of 0.2 yuan. This fee is borne by the courier. The current consumer from this Fengchao Express Cabinet Extracting the package is free.

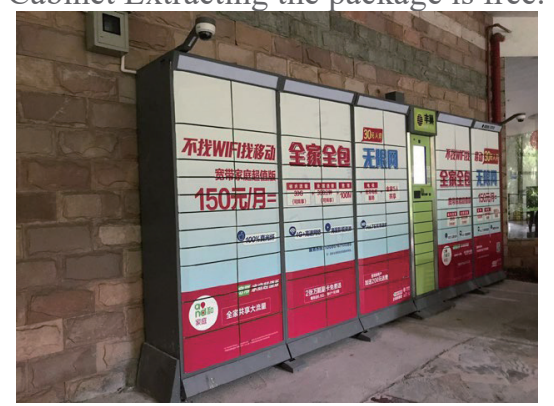

Figure 1, Fengchao intelligent express cabinet

\subsection{Storage of parcels}

Fengchao intelligent express cabinet is a fully enclosed structure of metal material, so it is safer to store in the smart cabinet, and it can also protect the consumer information. The storage in the lobby is not so optimistic. Because the lobby is a public space and is located in the only entrance hall, the crowd is crowded and the parcel is facing the possibility of being mistakenly stolen or stolen. Even if the parcel can be stored safely, it faces the situation that the personal information on the outer packaging is exposed to the open space. In the observation, it was also found that children lost the parcel as a toy. According to one of the courier feedback, an average package was lost every month in his lobby delivery.

\subsection{Package Packaging}

At present, the packaging materials used by domestic express delivery companies mainly include express waybills, envelopes, cartons, logo stickers, woven bags, plastic bags, bubble films, air column bags, foamed plastics, tapes, wooden boxes, etc. The parcels stored on the ground in the lobby are mainly packaged in corrugated cardboard boxes and plastic bags. As shown in Figure 2, there are also woven bags, bubble films, cardboard paper bags and other packaging. The recipient's name, address and telephone information will be clearly displayed on the outer packaging without any protective measures.

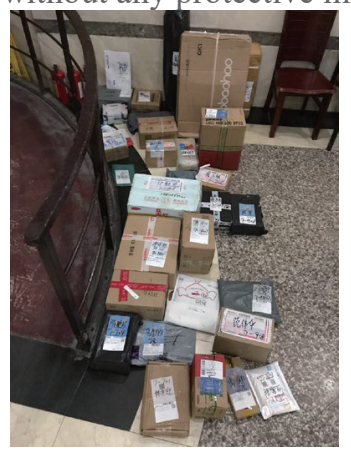

Fig. 2 the express parcel from the lobby

\subsection{Recycling of express packaging}

The garbage collection bins in this residential area are set up in the safety stairwells of each floor of the residential building. Every day, a large number of various disassembled express packaging packages appear here. The used packaging is not classified according to the materials, and is not seen in the observation. The courier's action to recycle the express package. According to statistics, China's annual solid waste exceeds 600 million tons, of which packaging waste accounts for $1 / 3$, and the recovery rate is less than $40 \%$.

\section{Analyses}

In the public open space to store personal courier parcels, you first need the courier to do the protection of personal information. You can learn from the QR code of Jingdong's outer packaging. Only the full-time courier can use the electronic scanning equipment to interpret the address of the recipient's telephone address in the QR code, and others cannot obtain this information.

Secondly, the storage in the open environment is easy to lose, so the setting of the Fengchao smart cabinet is best determined according to the actual needs to meet the practical application of the market. Finally, the parcel occupies the traffic space in the lobby, which is a safety hazard to a certain extent. It is recommended that the property management department of the residential area should conduct safety management. 


\section{Undergraduate Packaging Design Reform}

The traditional packaging design course focuses on the graphics, text, color, and how to better protect the product. Because of the time set in traditional packaging courses, there is not a lot of e-commerce. With the huge change in the current sales method, the original sales rely on the store to transfer to the e-commerce platform of Internet technology. As a result, the demand for packaging has also changed. Product packaging protection, environmental friendliness and information security on the packaging become more important.

In order to solve the problem of packaging materials existing in the above express packaging, increase the application of environmentally friendly materials in packaging design.

The generation of a large number of independent sales packages in the e-commerce sector also puts tremendous pressure on the environment. Therefore, it is particularly important to use consumable environmentally friendly materials. At present, the courses and practices of packaging materials are out of touch, and students often have little or no actual contact with real packaging materials.

For the information problems existing in express packaging, increase the application of intelligent in the teaching of packaging design. The text information on the existing packaging design is only for the packaging brand, product information and publicity information, and there is no information design specifically for logistics packaging. The application of artificial intelligence technology in packaging will be a direction in this aspect.

\section{In conclusion}

At present, most of the undergraduate packaging design courses stay in the field of traditional packaging, and in reality, because of the rise of e-commerce, the demand for packaging is subject to great changes. It is recommended to develop towards intelligent and environmentally friendly packaging design in teaching, with the premise of environmental protection and intelligent logistics as the goal. The government and the implementation of the teaching plan in the undergraduate packaging design course must guide this optimization work. I believe it is not far away. In the future, the packaging in the express delivery industry will have a qualitative leap.

\section{Reference}

[1][3] Wen Lina. Innovation and Development of Corrugated Packaging in the Internet Age[J]. Printing Technology, 2017.

[2] Li Wei. Research of the influence of situational factors on consumer impulse purchase about online shopping [D].

[4] Ruan Ping, Chen Lifang. Research on Green Driving Force of Express Packaging[J]. Logistics Technology, 2017. 
Educational Innovations and Applications- Tijus, Meen, Chang ISBN: 978-981-14-2064-1 